\title{
Highly Sensitive NH3 Detection Based on Organic Field Effect Transistors with Tris(pentafluorophenyl)Borane as Receptor
}

\author{
Weiguo Huang ${ }^{1}$, Kalpana Besar ${ }^{1}$, Rachel LeCover ${ }^{1}$, Ana María Rule ${ }^{2}$, Patrick N. Breysse ${ }^{2}$, \\ and Howard E. Katz ${ }^{1, *}$ \\ ${ }^{1}$ Department of Materials Science and Engineering, The Johns Hopkins University, 206 Maryland \\ Hall, 3400 North Charles Street, Baltimore, Maryland 21218, US \\ 2Department of Environmental Health Sciences, Bloomberg School of Public Health, Johns \\ Hopkins University, 615 North Wolfe Street, Baltimore, Maryland 21205, US
}

\begin{abstract}
We have increased organic field-effect transistor (OFET) NH3 response using tris(pentafluorophenyl)borane (TPFB) as receptor. OFETs with this additive detect concentrations of $450 \mathrm{ppb} v / \mathrm{v}$, with a limit of detection of $350 \mathrm{ppb}$, the highest sensitivity yet from semiconductor films; in comparison, when triphenylmethane (TPM) and triphenylborane (TFB) were used as an additive, no obvious improvement of sensitivity was observed. These OFETs also show considerable selectivity with respect to common organic vapors, and stability to storage. Furthermore, excellent memory of exposure was achieved by keeping the exposed devices in a sealed container stored at $-30^{\circ} \mathrm{C}$, the first such capability demonstrated with OFETs.
\end{abstract}

\begin{abstract}
Ammonia (NH3) detection has received considerable attention in the fields of agricultural environmental monitoring, chemical and pharmaceutical processing, and disease diagnosis. Existing methods have limitations. For example, mass spectrometry coupled with gas chromatography (GC-MS) and optical sensors is highly sensitive and selective, but is also expensive and not easily portable, and may be unwieldy for environmental monitoring. Organic field effect transistor (OFET) sensors are proposed for gas sensing due to potential high sensitivity, low cost, low weight and potential to make flexible, ${ }^{1}$ large area or massproduced devices. Many attempts have been made to improve NH3 transistor-based sensors. Wei et al. developed single-crystalline micro/ nanostructures of perylenediimide derivatives with a fast response rate, $\mathrm{NH} 3$ sensitivity of $1 \%$, and long term stability; ${ }^{2}$ Bouvet et al. reported molecular semiconductor-doped insulator heterojunction transducers which can detect " $<200$ ppm" NH3 vapor; ${ }^{3}$ later, Bouvet et al. developed a novel semiconducting molecular material, $\mathrm{Eu}_{2}\left[\mathrm{Pc}(15 \mathrm{C} 5)_{4}\right]_{2}\left[\mathrm{Pc}(\mathrm{OC} 10 \mathrm{H} 21)_{8}\right]$ as a quasi-Langmuir-Shäfer (QLS) film as a top-layer, and vacuum-deposited and cast film of $\mathrm{CuPc}$ as well as copper tetra-tertbutyl phthalocyanine (CuTTBPc) QLS film as sub-layers, achieving NH3 sensitivity in the range of $15-800 \mathrm{ppm} ;{ }^{4} \mathrm{Ju}$ et al. used poly-3-hexylthiophene (P3HT) as semiconductor and a thermally grown $\mathrm{SiO}_{2} / \mathrm{Si}$ wafer as substrate, successfully creating a high sensitivity $\mathrm{NH} 3$ sensor with a detect limitation of $10 \mathrm{ppm} ;{ }^{5} \mathrm{Zan}$ et al. developed pentacene based organic thin-film transistors which use UV treated PMMA [poly(methyl methacrylate)] as the buffer
\end{abstract}

Corresponding Author: hekatz@jhu.edu.

SUPPORTING INFORMATION AVAILABLE

Experimental details about NH3 and TPFB interaction, XPS data, typical transfer curves and output curves of CuPc and CoPc with and without additives, ATR and ${ }^{19}$ F NMR spectra of TPFB-NH3 complex, humidity experiment, sensing cycle data, determination of LOD experiments, memory behavior at different storage temperatures and a table of samples investigated are available in supporting information. This information is available free of charge via the Internet at http://pubs.acs.org/. 
layer to modify a $\mathrm{SiO}_{2}$ dielectric surface, and these sensors can respond to " $0.5 \mathrm{ppm}$ " $\mathrm{NH} 3 ; 6$ later, a novel hybrid gas sensor based on amorphous indium gallium zinc oxide thin-film transistors was developed by the same group, which can respond to " $0.1 \mathrm{ppm}$ " NH3. ${ }^{7}$ These latter detection limits are placed in quotes because in these experiments, the ppm concentration of NH3 gas in the chamber was expressed as mg per liter of chamber volume, ${ }^{6}$ which is 1329 times higher than a more appropriate ppm definition for gas mixtures $(\mu \mathrm{L} / \mathrm{L})$. Therefore, the detection of trace amount of NH3 by organic field effect transistors (sub ppm $\mathrm{v} / \mathrm{v}$ in the gas phase) is still challenging. Herein, we report OFET-based NH3 detectors with much higher sensitivity $(0.35 \mathrm{ppm} \mathrm{v/v)}$ than previously reported. We also demonstrate the enhancement conferred by tris(pentfluorophenyl) borane (TPFB) as an NH3 receptor, ${ }^{8}$ and the ability to store the exposed detector for later electronic assessment.

Boranes have frequently acted as complexation agents for Lewis bases ${ }^{9-13}$ due to the strong interaction between boron atoms and lone pairs; furthermore, borane-amine complexes were also widely used as light-emitting molecules ${ }^{14}$ and in fluorescent sensors. ${ }^{15}$ TPFB is frequently used as a strongly Lewis acidic co-catalyst in numerous reactions, such as dehydration, ${ }^{16}$ Friedel-Crafts reactions, ${ }^{17}$ ring-opening reactions, ${ }^{18}$ and syndiospecific living polymerization. ${ }^{19}$ Here, TPFB was chosen as the NH3 receptor additive to the OFET semiconductors due to the strong interaction between boron atoms and nitrogen atoms ${ }^{20}$ and the known vacuum sublimability of TPFB. Furthermore, the hydrogen bonds formed between hydrogen and fluorine atoms also play a role in the complexation process, with the NH3 molecule tightly bound to TPFB through all its four atoms (Scheme 1).

The strong interaction between NH3 and TPFB is also confirmed by previous reports ${ }^{20,21}$ as well as the experiments described in the supporting information (Figure S1). A proposed structure of the precipitate is shown in Scheme 1, one NH3 molecule forming a complex with one TPFB molecule through B-N interaction and three hydrogen bonds. The structure is confirmed by ${ }^{19} \mathrm{~F}$ NMR and Attenuated Total Reflectance (ATR) spectra. These spectra agree with previous literature data. ${ }^{20,21}$

We used two OFET semiconductors, copper phthalocyanine $(\mathrm{CuPc})$ and cobalt phthalocyanine $(\mathrm{CoPc})$. As TPFB controls, triphenylmethane (TPM) and triphenyl-borane (TPB) were used as additives due to their similar molecular shapes with TPFB. All OFETs were fabricated and characterized using standard methods. Materials were purchased from Sigma-Aldrich. Highly n-doped $\langle 100\rangle$ silicon wafers with $300 \mathrm{~nm}$ thermally grown oxide were diced into $1 \mathrm{in}$. by $1 \mathrm{in}$. substrates, cleaned with piranha solution (Caution--corrosive!), sonicated in acetone and isopropanol, and then dried by forced nitrogen gas. Substrates were further dried by $100{ }^{\circ} \mathrm{C}$ vacuum annealing for 20 minutes prior to a 2-hour exposure to hexamethyldisilazane (HMDS) vapor at $110^{\circ} \mathrm{C}$ in a loosely sealed vessel. Organic semiconductors ( $\mathrm{OSCs}, \mathrm{CuPc}$ and $\mathrm{CoPc}$ ) were thermally evaporated neatly or co-evaporated with TPFB, TBP, or TPM directly onto HMDS-treated substrates with a thickness of $6 \mathrm{~nm}$ at a rate of $0.3 \AA$ /s for the OSCs, while the deposition rate of additive was $0.2 \AA$ Á/s. Gold electrodes $(50 \mathrm{~nm}$ ) were thermally vapor-deposited through a mask (channel width/length (W/L) 32) at $0.3 \AA$ s. The deposition chamber pressure was $<5 \times 10^{-6}$ torr, and substrate temperature during the deposition was held constant at $25^{\circ} \mathrm{C}$. OSC-containing film compositions were examined by x-ray photoelectron spectroscopy (XPS); the results are shown in Figure S2. Fluorine element peaks (between 680 and 700) are seen in the spectra of CuPc\&TPFB and CoPc\&TPFB, while no fluoride element peak appears in the spectra of $\mathrm{CuPc}$ and CoPc. All the OFETs were measured using an Agilent 4155C semiconductor analyzer. $\mathrm{NH} 3$ gas with a certified dilution (4.5 ppm in nitrogen) was purchased from PRAXAIR; $0.45 \mathrm{ppm} \mathrm{NH3}$ concentration was achieved by mixing the $4.5 \mathrm{ppm} \mathrm{NH3}$ with pure nitrogen and assayed using a photoionization detector (PID) (Pho Check Tiger, Ion Science, UK). A sealed exposure chamber with a volume of 4 liters was used, with a rotating 
fan inside to create a uniform vapor concentration; the flow rate of gas through the chamber was 0.2 liters per minute.

Typical OFET transfer/output curves of CuPc and CoPc with and without additives are shown in Figure $\mathrm{S} 3$ (drain voltage $\mathrm{V}_{\mathrm{ds}}=-60 \mathrm{~V}$ ) and Figure $\mathrm{S} 4$, respectively. Mobilities, threshold voltages and on-off current ratios of these transistors are summarized in Table S2. OFETs with TPFB as additive show lower mobility and require higher gate voltage to turn on than the other OFETs. One possible reason may be that TPFB contains many more locally dipolar bonds than TPM and TPB, which makes it more likely for TPFB to trap holes in the channel, thus giving lower mobility and lower threshold voltage.

The responses of these devices to NH3 vapor were investigated; the percentage of drain current change $\mathrm{I} / \mathrm{I}_{\mathrm{o}}$ (gate voltage $\mathrm{V}_{\mathrm{g}}=-60 \mathrm{~V}, \mathrm{~V}_{\mathrm{ds}}=-60 \mathrm{~V}$ ) are all plotted with respect to time of exposure to NH3 vapor. For some p-type semiconductors, such as $\mathrm{CuPc}, \mathrm{CoPc}$, 6PTTP6, and pentacene, ${ }^{22-25}$ the OFET current is known to be higher in dry air due to oxygen doping than in nitrogen, the carrier gas used for NH3. In order to obtain accurate and reproducible responses to $\mathrm{NH} 3$, all devices were subjected to ambient aging for 3 days before NH3 exposure experiments. The responses shown in the following figures are corrected for the current decrease caused by replacing oxygen with nitrogen.

As shown in Figure 1(a) and (b), after exposure to 4.5 ppm NH3 vapor for 30 minutes, the drain current of CuPc, CuPc\&TPM and CuPc\&TPB decreased 13\%, 12\% and 16\% respectively. For $\mathrm{CuPc} \& \mathrm{TPFB}$, the decrease in drain current was 33\%, which is much higher than the responses of CuPc, CuPc\&TPM and CuPc\&TPB. For CoPc, CoPc\&TPM and CoPc\&TPB, the decrease was $11 \%, 15 \%$ and $16 \%$ respectively, and for CoPc\&TPFB, the decrease was $37 \%$, which is also much higher than for CoPc, CoPc\&TPM and CoPc\&TPB. This larger decrease is consistent with the strong interaction between TPFB and NH3 vapor increasing the binding of NH3 to the semi-conductor surface, thus giving a much higher relative response. While TPM has a similar molecular structure as TPFB, it has no hostguest interaction with $\mathrm{NH} 3$, and the enhancement in relative response was not obtained. Although TPB has a boron atom in the molecular center, it is a much weaker lewis acid compared to TPFB, ${ }^{26}$ moreover, there is no hydrogen bonding between TPB and NH3, therefore, the response is also much lower than the response of TPFB. After 90 minutes of exposure, the decreases in drain current of CuPc, CuPc\&TPM, CuPc\&TPB and CuPc\&TPFB were $24 \%, 15 \%, 28 \%$ and $41 \%$ respectively. For CoPc, CoPc\&TPM, CoPc\&TPB and CoPc\&TPFB, the decreases were 16\%, 22\%, 23\% and 44\%, respectively. After 260 minutes of exposure, the drain current of CuPc, CuPc\&TPM, CuPc\&TPB and CuPc\&TPFB decreased by 38\%, 25\%, $40 \%$ and 51\% respectively. For CoPc, CoPc\&TPM, CoPc\&TPB and CoPc\&TPFB, the drain current decreased by $24 \%, 31 \%, 33 \%$ and $63 \%$ respectively. Over time, the rate of drain current decrease became lower. A listing of the numbers of different evaporations, wafers and devices used in this study is summarized in Table S1.

Sensing cycle experiments were also done (Figure S5). In this set of experiments, NH3 exposure time is 90 seconds, the devices give instant responses, and recover immediately after airflow over the devices' surface. The recovery takes a relatively long time only when the responses are high $(>30 \%)$. Within the range of concentrations measured $(0.45 \mathrm{ppm}-20$ ppm), we observe a relatively linear change in response. Therefore, the devices give an instantaneous response and reflect the real concentration of the analyte in the air. At later stages, the system works according to an accumulative model.

In a third set of experiments, CuPc\&TPFB and CoPc\&TPFB were exposed to a much lower NH3 concentration ( $0.45 \mathrm{ppm}$ in nitrogen), and the results are shown in Figures 1(c) and (d). 
After 5 minutes' exposure, the drain current of CuPc\&TPFB and CoPc\&TPFB decreased by $13 \%$ and $12 \%$ respectively, while after 10 minutes, the drain currents decreased by $21 \%$ and 23\%; after 20 and 30 minutes exposure, the drain current of CuPc\&TPFB and CoPc\&TPFB decreased $23 \%$ and $26 \%$, and $27 \%$ and $28 \%$ respectively. In comparison, responses of CuPc\&TPFB and CoPc\&TPFB to 4.5 ppm NH3 after 5, 10, 20, and 30 minutes are also shown in Figures 1(c) and (d). While the higher concentration gives greater response, the time for equilibration may be increased because of barriers to $\mathrm{NH} 3$ reaching some of the sites complexed with higher concentrations. Additionally, we have also exposed the device to $0.35 \mathrm{ppm}$ and $0.25 \mathrm{ppm} \mathrm{NH3}$, the results were summarized in Table S3. According to the definition of limit of detection ${ }^{25,27}$ ( $\mathrm{LOD}=\mathrm{R}_{\text {blank }}+3 \mathrm{~S}$; " $\mathrm{R}_{\text {blank }}$ " is blank response, " $\mathrm{S}$ " is standard deviation of response), we get a conservative estimate value of limit of detection is $0.35 \mathrm{ppm}$.

The selectivity of these devices was also investigated. Figure 2 displays the drain current change of CuPc\&TPFB and CoPc\&TPFB after exposure to different gas vapors. Methanol, acetone and ethyl acetate were chosen due to oxygen interactions with TPFB between $\mathrm{O}$ and $\mathrm{B}$ atoms. ${ }^{28}$ Dichloromethane is a highly volatile solvent, it may exist in some circumstances at high concentration, so it is desirable to check this vapor. As shown in figure 2, all these solvents give only small responses even at very high concentrations (several thousands $\mathrm{ppm}$ ). The devices are also stable to high hydrogen concentration. It is not surprising that these devices are sensitive to volatile amines; however, the responses are smaller than the response to $\mathrm{NH} 3$ (4.5ppm $\mathrm{NH}_{3}$ vs $10 \mathrm{ppm}$ isopropylamine or $10 \mathrm{ppm}$ isobutylamine). ${ }^{8}$ The possible reason may be the alkyl chain of the amines causing steric hindrance while binding with TPFB, resulting in a relatively longer B-N bond than that of $\mathrm{NH} 3,{ }^{20}$ thus give lower responses than NH3. Another reason may be one TPFB molecule can bind with two NH3 molecules, ${ }^{20}$ while there is no prior report that one TPFB can bind with two amine molecules; so TPFB is more sensitive and efficient to detect NH3 vapor than organic amine vapors. For $\mathrm{H}_{2} \mathrm{~S}$, these devices also show relatively high responses, however, the responses are also lower than the responses of $\mathrm{NH} 3$. Furthermore, $\mathrm{H}_{2} \mathrm{~S}$ is an acidic gas, while $\mathrm{NH} 3$ is basic gas. Due to their significantly different properties, it is easy to selectively filter $\mathrm{H}_{2} \mathrm{~S}$ with basic powder, the same method used in some previous literature. ${ }^{29,30}$ These devices also shown good stablity to moisture, the drain current can maintain above $50 \%$ of its original value even after 7 days exposures to lower than $30 \%$ relative humidity (RH) at 25 ${ }^{\circ} \mathrm{C}$; only when the $\mathrm{RH}$ is higher than $50 \%$, the devices show relative fast linear decay (Figure S6). Water is also filterable from NH3, using a highly basic dessicant.

Retention of the exposure effect is important if reading the device right after exposure is impractical. Diffusion of the analyte out of the device or even within the device must be prevented. Maintaining the NH3-exposed device in open air, or in a sealed, air-filled container ( 1 " diameter Fluoroware) at room temperature, was insufficient to keep the postexposure current constant. However, by placing the exposed devices in the container and storing at low temperature $\left(-30{ }^{\circ} \mathrm{C}\right)$, the signal change after one day is small. As shown in Figure 3, for CuPc\&TPFB, an exposed device with a response of $70 \%$ drain current decrease gradually lost its response signal while stored in open air; the device stored in the container at $25{ }^{\circ} \mathrm{C}$ showed a signal change from $47 \%$ to $83 \%$ after 24 hours, perhaps because of NH3 diffusion within the device to more electronically active sites. However, for the device stored in the container at $-30^{\circ} \mathrm{C}$, the signal only showed an insignificant change after 24 hours, from $44 \%$ to $45 \%$. For CoPc\&TPFB, the device stored in open air also lost its signal and recovered eventually; the device stored in the container at $25^{\circ} \mathrm{C}$ showed a signal change from $30 \%$ to $66 \%$ after 24 hours; while for the device stored in the container at $-30{ }^{\circ} \mathrm{C}$, the signal showed a negligible change, from $31 \%$ to $33 \%$. The change after one day of storage in the container at $-30{ }^{\circ} \mathrm{C}$ is less than $3 \%$ of the original current, and invariably less than $6 \%$ 
of the original current, even for responsive current changes $>50 \%$. Drain current change after 24 hours at other storage temperatures is shown in Figure S7.

In conclusion, we have successfully developed a highly responsive $\mathrm{NH} 3$ detector using TPFB as a receptor. OFETs using this additive can detect concentrations at least as low as $450 \mathrm{ppb} v / \mathrm{v}$, and with a LOD value of $0.35 \mathrm{ppm}$. In comparison, when TPM and TPB were used as additives, no obvious improvement in sensitivity was observed. The specific hostguest interaction between NH3 and TPFB appears to be critical for the enhancement observed relative to neat semiconductors. Additionally, these OFETs also show good selectivity and storage stability. Device current changes were preserved by keeping the devices in a sealed container stored at $-30^{\circ} \mathrm{C}$. To the best of our knowledge, this is the first report of using borane as a receptor in a sensitive organic field effect transistor, the first use of OFETs to record responses to vapors, and the most sensitive semiconductor-based NH3 detection demonstrated to date.

\section{Supplementary Material}

Refer to Web version on PubMed Central for supplementary material.

\section{Acknowledgments}

We thank Dr. Jasmine Sinha for help with editing. We are grateful to JHSPH Center for a Livable Future, NIEHS Center in Urban Environmental Health - P30 ES 03819, and Johns Hopkins Environment, Energy, Sustainability \& Health Institute for support of this work.

\section{References}

1. a) Mabeck JT, Malliaras GG. Anal Bioanal Chem. 2006; 384:343. [PubMed: 16079978] b) Torsi L, Dodabalapur A, Sabbatini L, Zambonin PG. Sensor Actuat B-Chem. 2000; 67:312.c) Crone B, Dodabalapur A, Gelperin A, Torsi L, Katz HE, Lovinger AJ, Bao Z. Appl Phys Lett. 2001; 78:2229.d) See KC, Becknell A, Miragliotta J, Katz HE. Adv Mater. 2007; 19:3322.e) Huang J, Dawidczyk TJ, Jung BJ, Sun J, Mason AF, Katz HE. J Mater Chem. 2010; 20:2644.f) Someya T, Dodabalapur A, Huang J, See KC, Katz HE. Adv Mater. 2010; 22:3799. [PubMed: 20603885] g) Huang J, Sun J, Katz HE. Adv Mater. 2008; 20:2567.h) Huang J, Miragliotta J, Becknell A, Katz HE. J Am Chem Soc. 2007; 129:9366. [PubMed: 17625846] i) Hammock ML, Sokolov AN, Stoltenberg RM, Naab BD, Bao ZN. ACS Nano. 2012; 6:3100. [PubMed: 22397363] j) Khan HU, Roberts ME, Knoll W, Bao ZN. Chem Mater. 2011; 23:1946.k) Roberts ME, LeMieux MC, Bao ZN. ACS Nano. 2009; 3:3287. [PubMed: 19856982] 1) Torsi L, Farinala GM, Marinelli F, Tanese MC, Omar OH, Valli L, Babudri F, Palmisano F, Zambonin PG, Naso F. Nat Mater. 2008; 7:412. [PubMed: 18425136] m) Kim C, Wang ZM, Choi HJ, Ha YG, Facchetti A, Marks TJ. J Am Chem Soc. 2008; 130:6867. [PubMed: 18454529]

2. Huang YW, Fu L, Zou WJ, Zhang FL, Wei ZX. J Phys Chem C. 2011; 115:10399.

3. Bouvet M, Xiong H, Parra V. Sensors Actuat B-Chem. 2010; 146:501.

4. Chen YL, Bouvet M, Sizun T, Barochi G, Rossignol J, Lesniewska E. Sensors Actuat B-Chem. $2011 ; 155: 165$.

5. Jeong JW, Lee YD, Kim YM, Park YW, Choi JH, Park TH, Soo CD, Won SM, Han IK, Ju BK. Sensors Actuat B-Chem. 2010; 146:40.

6. Zan H-W, Tsai W-W, Lo Y-r, Wu Y-M, Yang Y-S. IEEE Sensors J. 2012; 12:594.

7. Zan HW, Li CH, Yeh CC, Dai MZ, Meng HF, Tsai CC. Appl Phys Lett. 2011; 98:253503.

8. Esser B, Schnorr JM, Swager TM. Angew Chem, Int Ed Engl. 2012; 51:5752. [PubMed: 22517760]

9. Steed, JW.; Atwood, JL. Supramolecular Chemistry. Wiley-Chichester; UK: 2000.

10. Hughes CC, Scharn D, Mulzer J, Trauner D. Org Lett. 2002; 2:4109. [PubMed: 12423098]

11. Reetz MT, Niemeyer CM, Hermes M, Goddard R. Angew Chem, Int Ed Engl. 1992; 32:1017.

12. Reetz MT, Huff J, Goddard R. Tet Lett. 1994; 35:2521. 
13. Carboni B, Monnier L. Tetrahedron. 1999; 55:1197.See also: Huskens J, Goddard R, Reetz MT. J Am Chem Soc. 1998; 120:6617.Nozaki K, Tsutsumi T, Takaya H. J Org Chem. 1995; 60:6668.

14. Goeb S, Ziessel R. Org Lett. 2007; 9:737. [PubMed: 17269781]

15. Zhang XF, Liu XL, Lu R, Zhang HJ, Gong P. J Mater Chem. 2012; 22:1167.

16. Wanglee YJ, Hu J, White RE, Lee MY, Stewart SM, Perrotin P, Scott SL. J Am Chem Soc. 2012; 134:355. [PubMed: 22106984]

17. Thirupathi P, Neupane LN, Lee K-H. cheminform. 2012; 43 ASAP. 10.1002/chin.201205089

18. Watson IDG, Yudin AK. J Org Chem. 2003; 68:5160. [PubMed: 12816471]

19. Kawabe M, Murata M, Soga K. Macromol Rapid Commun. 1999; 20:569.

20. Mountford AJ, Lancaster SJ, Coles SJ, Horton PN, Hughes DL, Hursthouse MB, Light ME. Inorg Chem. 2005; 44:5921. [PubMed: 16060648]

21. Massey AG, Park AJ. J Organometal Chem. 1964; 2:245.

22. Park J, Royer JE, Colesniuc CN, Bohrer FI, Sharoni A, Jin S, Schuller IK, Trogler WC, Kummel AC. J Appl Phys. 2009; 106:034505.

23. Bohrer FI, Sharoni A, Colesniuc CN, Park J, Schuller IK, Kummel AC, Trogler WC. J Am Chem Soc. 2007; 129:5640. [PubMed: 17411043]

24. Bohrer FI, Colesniuc CN, Park J, Ruidiaz ME, Schuller IK, Kummel AC, Trogler WC. J Am Chem Soc. 2009; 131:478. [PubMed: 19093852]

25. Bohrer FI, Colesniuc CN, Park J, Schuller IK, Kummen AC, Trogler WC. J Am Chem Soc. 2008; 130:3712. [PubMed: 18321103]

26. Tanaka Y, Hasui T, Suginome M. Synlett. 2008; 8:1239.

27. Khalil OS. Clin Chem 45. 1999; 2:165.

28. Saverio AD, Focante F, Camurati I, Resconi L, Beringhelli T, D’Alfonso G, Donghi D, Maggioni D, Mercandelli P, Sironi A. Inorg Chem. 2005; 44:5030. [PubMed: 15998031]

29. Brunet J, Pauly A, Mazet L, Germain JP, Bouvet M, Malezieux B. Thin Solid Films. 2005; 490:28.

30. Viricelle JP, Pauly A, Mazet L, Brunet J, Bouvet M, Varenne C, Pijolat C. Mater Sci Eng C. 2006; 26:186. 

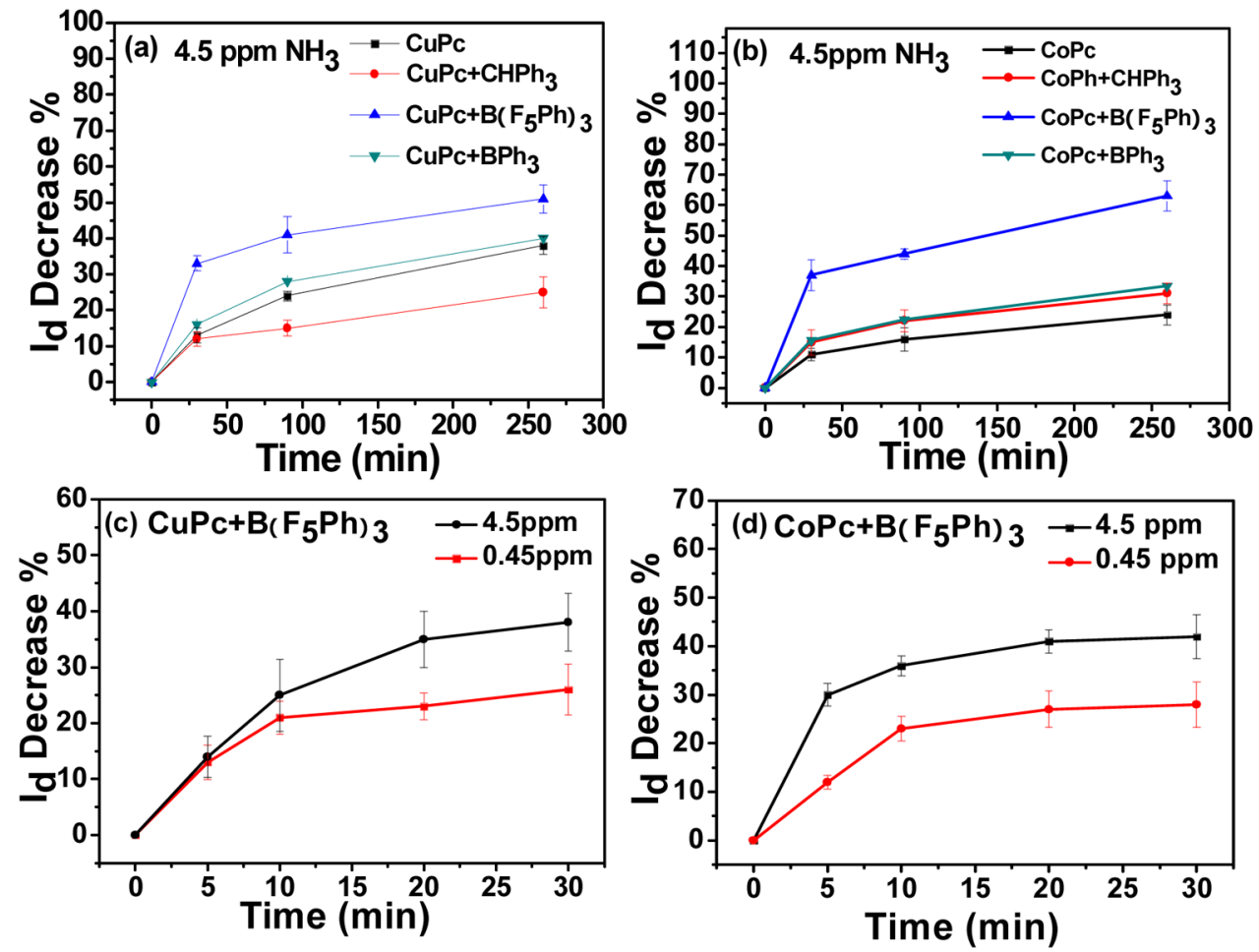

Figure 1.

Drain current decrease of (a) CuPc, CuPc\&TPM, CuPc\&TPFB and CuPc\&TPB devices and (b) CoPc, CoPc\&TPM, CoPc\&TPFB and CoPc\&TPB devices after different times of exposure to 4.5 ppm NH3; Drain current decrease of (c) CuPc\&TPFB device and (d)

CoPc\&TPFB device after different times of exposure to $4.5 \mathrm{ppm}$ and $0.45 \mathrm{ppm} \mathrm{NH3}$ vapor. 


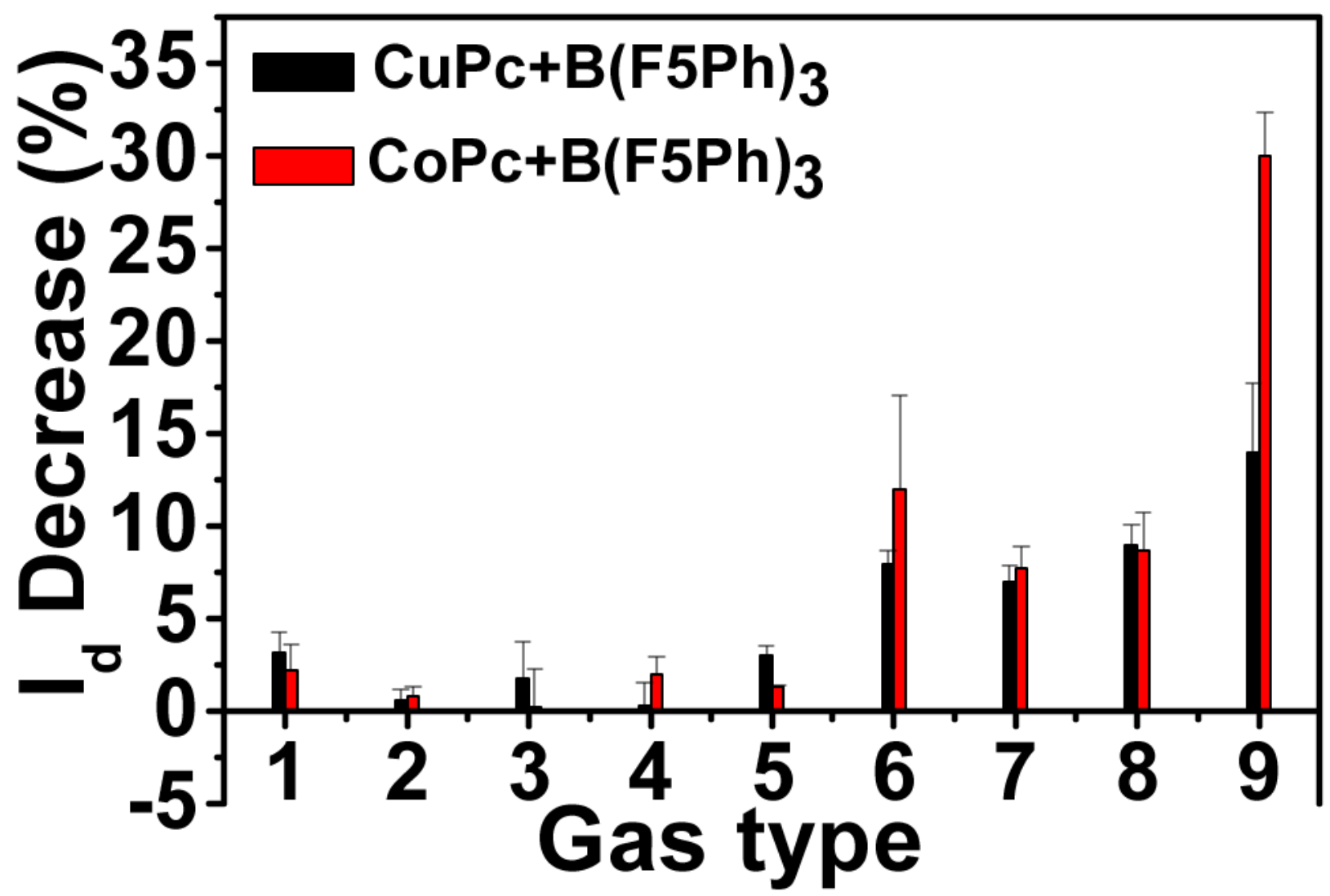

Figure 2.

Drain current change of CuPc\&TPFB and CoPc\&TPFB devices in different gas vapor for 5 minutes; 1, methanol (2000 ppm); 2, acetone (1800 ppm); 3, dichloromethane (3900 ppm); 4, ethyl acetate (1500 ppm); 5, 5\% $\mathrm{H}_{2}(50000 \mathrm{ppm}) ; 6$, isopropylamine (10ppm); 7 , isobutylamine (10ppm); 8, $\mathrm{H}_{2} \mathrm{~S}(5 \mathrm{ppm}) ; 9, \mathrm{NH}_{3}(4.5 \mathrm{ppm})$. 

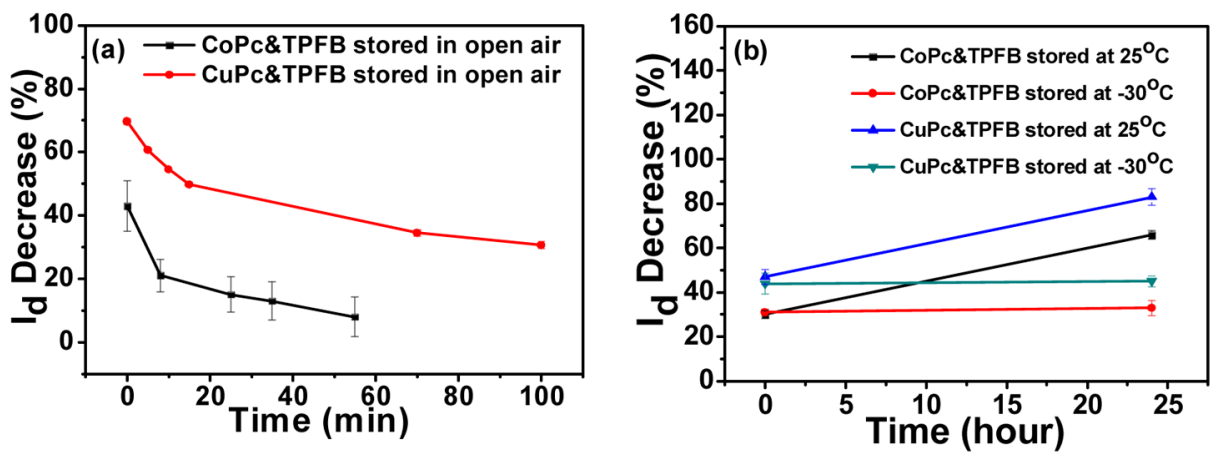

Figure 3.

Current change of differently stored devices. 

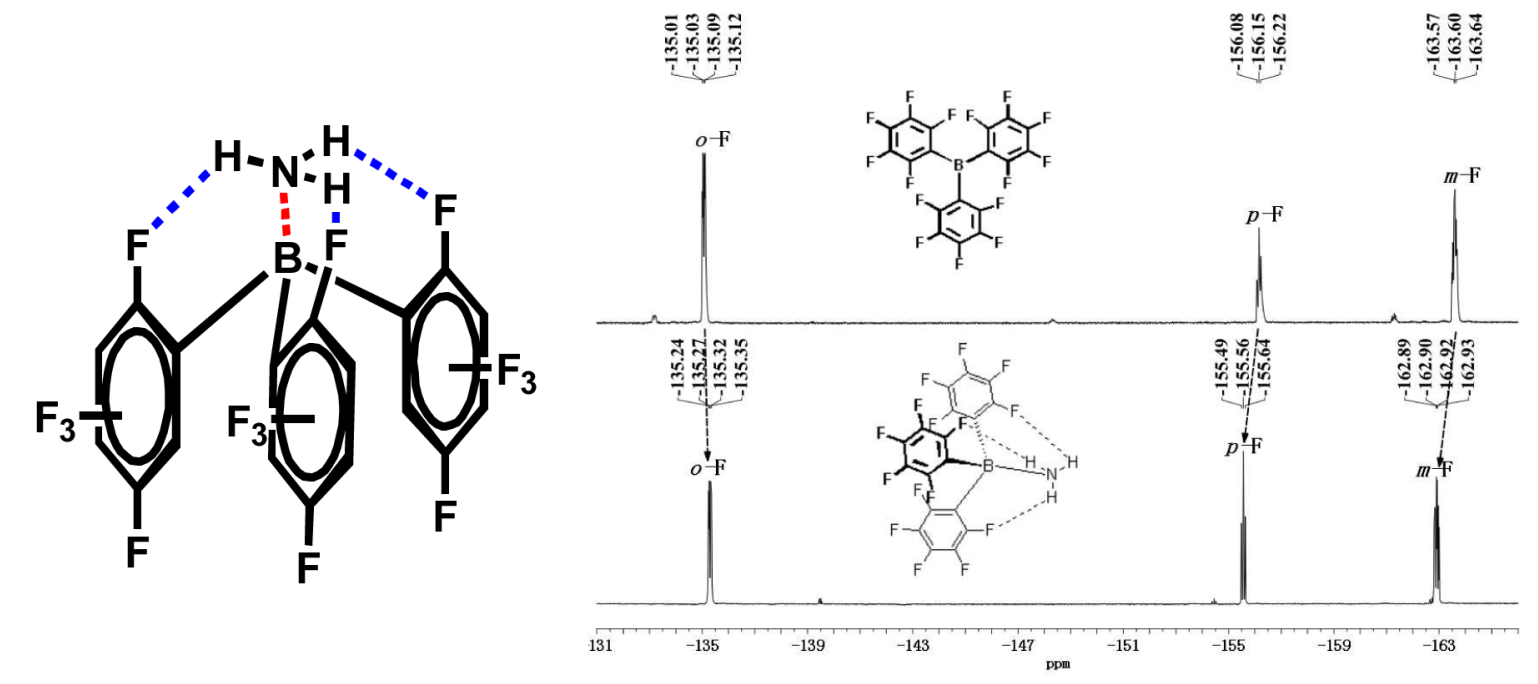

Scheme 1.

NH3-tris (pentflurophenyl) borane interaction; ${ }^{19} \mathrm{~F}$ NMR spectra of tris (pentflurophenyl) borane and borane NH3 complex. (blue bonds: hydrogen bonding, red bonds: B-N interaction) 